UDC $004.942:: 539.621: 517.958: 517.442$

\title{
Mathematical modelling of thermoelastic behavior of a coating taking into account frictional heating and wear ${ }^{*}$
}

\section{B. Zelentsov, B. I. Mitrin, I. A. Lubyagin, S. M. Aizikovich**}

Don State Technical University, Rostov-on-Don, Russian Federation

This work describes application of the integral transform method to solution of a quasi-static contact problem of the coating wear-out. Frictional heating and wear of the coating occurs during the sliding of a rigid body over its surface. The problem is considered in the framework of the coupled thermoelasticity theory. The solution of the problem is constructed in the form of contour quadratures of the inverse Laplace transformation. After the calculation of the quadratures the solution of the problem is constructed in the form of series over the poles of the integrands. Investigation of the poles of integrands is performed in dependence on four dimensionless parameters of the problem. The solutions obtained are studied in detail with respect to the dimensionless and dimensional parameters of the problem. Numerical examples of the obtained solutions for contact stresses, displacements, temperature and wear of the coating are presented.

Keywords: coating, friction, wear, frictional heating, thermoelasticity, Laplace transform, contour integral

Introduction. The study of thermoelasticity problems, taking into account the interaction of deformation and temperature fields, began with [1-3]. This line of research was called the coupled thermoelasticity. Generalization and solution of particular problems of the new direction of research was continued in [3-5]. In subsequent years, both analytical, starting with [4, 5], and numerical methods [6] were developed to solve problems of coupled thermoelasticity. In the latter paper the authors were one of the first who developed a scheme of application of the finite element method and gave its implementation for solving the coupled problems of thermoelasticity. Analysis shows that in the overwhelming majority of studies in the solution of coupled thermoelasticity problems the finite element models of a fairly general purpose were developed, for example [7-11].The analytical methods for solving this class of problems did not become as widespread as the numerical ones. The results obtained with their help were summarized in [12]. Beginning with papers [13-18], scientists consider uncoupled problems of thermoelasticity about the sliding contact of a rigid body with an elastic coating, taking into account friction, heating of the coating from friction, and abrasive wear. Because of the large number of parameters of the problem, the onedimensional and quasi-static problems were considered. In [15-18], for their solution the integral Laplace transform with a solution in the form of functional series along the poles of the integrands of the contour quadratures of the inverse Laplace transform were used. The solution method allows

\footnotetext{
* The work was carried out within the framework of the Governmental Assignment of the Ministry of Education and Science of the Russian Federation no. 9.1481.2017/4.6 and RFBR grants nos. 16-07-00929-a, 17-07-01376-a.

**E-mail: vbzelen@gmail.com, bmitrin@dstu.edu.ru, hammavet@gmail.com, saizikovich@gmail.com
} 
establishing the parametric boundaries of the thermoelastic instability of a sliding contact, to investigate the properties of the solutions obtained. Beginning with [20-22], a new direction of the development of the model of the sliding contact of two elastic bodies arose, taking into account friction, wear and heat generation, built on the principle of virtual energy and the basic laws of thermodynamics. The solution of problems on the basis of this model is carried out by the finite element method [22]. The present paper demonstrates the application of the Laplace integral transform and complex analysis methods to solution of the coupled thermoelastic problem on the coating wear occurring during sliding frictional contact with frictional heating.

1. Statement of the coupled problem of wear. To investigate the effect of thermoelastic coupling on the occurrence of thermoelastic instability in sliding contact problems, the contact problem of coupled thermoelasticity about sliding with a constant velocity $V$ of a rigid heatinsulated half-plane $I(h \leq x<\infty)$ over the upper $(x=h)$ surface of an elastic thermal-conducting coating of thickness $h(0 \leq x \leq h)$, is considered. The lower surface of the coating is rigidly coupled to a non-deformable non-heat-conducting substrate in the form of a half-plane II $(\infty<x<0)$. Sliding of the half-plane $I$ along the surface of the elastic coating takes into account Coulomb friction and abrasive wear of the coating surface [15-19]. The heat flux generated at the contact due to friction is directed into the coating. From the initial instant of time, the half-plane $I$ moving along the axis $y$ deforms the surface $(x=h)$ of the elastic coating, moving in the direction opposite to the axis $x$, according to the law $\Delta(t)$. Until the initial moment, the coating was at rest, and its temperature was equal to $T_{0}$.

The formulation of the problem assumes that the distribution of temperature, stresses and displacements in the coating does not depend on the choice of the horizontal coordinate along the axis $y$ parallel to the direction of motion of the half-plane $I$, and are functions of only the $x$ coordinate and time $t$ [15-19]. Two-dimensional differential equations of the theory of elasticity in the case of quasi-static and in the absence of mass forces, describing the stress-strain state of the coating, take the form

$$
\frac{\partial \sigma_{x x}}{\partial x}=0, \quad \frac{\partial \sigma_{x y}}{\partial x}=0, \quad 0 \leq x \leq h, \quad t>0
$$

where $\sigma_{x x}=\sigma_{x x}(x, t), \sigma_{x y}=\sigma_{x y}(x, t)$ - normal and tangential stresses in the coating.

The temperature in the coating is described by the equation of thermal conductivity [23]

$$
\frac{\partial^{2} T}{\partial x^{2}}-\frac{1}{\kappa} \frac{\partial T}{\partial t}=\alpha \frac{3 \lambda+2 \mu}{K} T_{0} \frac{\partial \varepsilon_{x x}}{\partial t} \quad 0 \leq x \leq h, \quad t>0
$$

where $T(x, t)$ - temperature distribution in the coating, $\kappa$ - coefficient of thermal diffusivity, $\alpha-$ coefficient of linear expansion of coating material, $\lambda, \mu$ - Lame coefficients, $K$ - coefficient of thermal conductivity, $T_{0}$ - initial temperature in the coating, $\varepsilon_{x x}$ - deformation of the coating along the $x$ axis.

The relationship between stresses and strains is determined from a form of the Hooke's law: 


$$
\sigma_{x x}=(\lambda+2 \mu) \varepsilon_{x x}-(3 \lambda+2 \mu) \alpha\left(T-T_{0}\right), \quad \sigma_{x y}=\mu \varepsilon_{x y}
$$

in which the deformations in our case are expressed in terms of the displacements by the following formulas

$$
\varepsilon_{x x}=\frac{\partial u}{\partial x}, \quad \varepsilon_{x y}=\frac{\partial w}{\partial x}
$$

where $u(x, t), w(x, t)$ - vertical and horizontal displacements in the coating.

The relations (1.4) are substituted in (1.3), after which (1.3) is substituted into the differential equations of the theory of elasticity (1.1) to obtain the equations of thermoelasticity

$$
\frac{\partial^{2} u}{\partial x^{2}}=\frac{1+v}{1-v} \alpha \frac{\partial T}{\partial x}, \quad \frac{\partial^{2} w}{\partial x^{2}}=0, \quad 0 \leq x \leq h, \quad t>0
$$

Differential equations of coupled thermoelasticity are represented by a system of differential equations of thermoelasticity (1.5) and the differential heat-transfer equation (1.2) describing the stress-strain state of an elastic coating. The boundary conditions of the problem for the differential equations (1.5), (1.2) are the following:

mechanical $t>0$

$$
\begin{aligned}
& x=h \quad u(h, t)=-\Delta(t)+u_{w}(t) \\
& \sigma_{x y}(h, t)=-f \sigma_{x x}(h, t) \\
& x=0 \quad u(0, t)=0 \\
& w(0, t)=0
\end{aligned}
$$

temperature $t>0$

$$
\begin{array}{ll}
x=h & K \frac{\partial T(h, t)}{\partial x}=-f V \sigma_{x x}(h, t) \\
x=0 & K \frac{\partial T(0, t)}{\partial x}=k\left(T(0, t)-T_{0}\right)
\end{array}
$$

where $f$ - coefficient of friction, $k$ - coefficient of heat transfer, $u_{w}(t)$ - half-plane $I$ displacement due to the wear of the coating. Further, the abrasive wear model [24] is used, according to which

$$
u_{w}(t)=-f V K^{*} \int_{0}^{t} \sigma_{x x}(h, \tau) d \tau \quad t>0
$$

where $\sigma_{x x}(h, t)$ - normal compressive stresses on the contact, $K^{*}$ - coefficient of proportionality between the work of frictional forces and the amount of material removed from contact. In addition, according to (1.10), it is assumed that all the heat at the contact is formed due to friction.

The initial conditions for displacement in the coating are zeros

$$
u(x, 0)=\frac{\partial u(x, 0)}{\partial t}=w(x, 0)=\frac{\partial w(x, 0)}{\partial t}=0, \quad \Delta(0)=0
$$

and the initial conditions for temperature are nontrivial 


$$
T(x, 0)=T_{0}
$$

Thus, the solution of the formulated coupled contact problem of thermoelasticity for the wear of an elastic coating on the sliding contact between a rigid body and an elastic coating, taking into account the heating from friction, is reduced to solving the system of differential equations (1.2), (1.5) with the boundary (1.6) - (1.11) and initial conditions (1.13), (1.14). It should be noted that the vertical displacements $u(x, t)$, normal stresses $\sigma_{x x}(x, t)$ and temperature $T(x, t)$ in the coating are determined independently from the horizontal displacements $w(x, t)$. Horizontal displacements $w(x, t)$ are determined from (1.5), (1.7), (1.9) using normal stresses.

2. Exact solution of the problem. The solution of the coupled contact thermoelasticity problem given in $\S 1$ is constructed using the Laplace integral transformation [25]:

$$
u^{L}(x, p)=\int_{0}^{\infty} u(x, t) e^{-p t} d t, \quad u(x, t)=\frac{1}{2 \pi i} \int_{-i \infty+c}^{i \infty+c} u^{L}(x, p) e^{p t} d p \quad \operatorname{Re} p<c, c>0
$$

The index in (2.1) denotes the transform of the Laplace transformation.

The Laplace transformation (2.1) is applied to the differential equations (1.2), (1.5) taking into account the initial conditions (1.13), (1.14) and the existence conditions for the Laplace integrals (2.1) [25]. As a result, we obtain a system of ordinary differential equations with respect to the transforms $u^{L}(x, p)$ and $T^{L}(x, p)$

$$
\begin{gathered}
\frac{d^{2} u^{L}}{d x^{2}}=\frac{1+v}{1-v} \alpha \frac{d T^{L}}{d x} \quad 0 \leq x \leq h \\
\frac{d^{2} T^{L}}{d x^{2}}-\frac{p}{\kappa} T^{L}-\frac{1}{\kappa} T_{0}=\frac{2 \mu(1+v)}{1-2 v} \frac{\alpha}{K} T_{0} p \frac{d u^{L}}{d x} \quad 0 \leq x \leq h
\end{gathered}
$$

Differentiating equation (2.3) and substituting the second derivative of $u^{L}(x, p)$ from (2.2) into the resulting relation, we obtain a differential equation with respect to $T^{L}(x, p)$

$$
\begin{aligned}
& \frac{d}{d x}\left(\frac{d^{2} T^{L}}{d x^{2}}-\frac{\beta^{2}}{\kappa} p T^{L}\right)=0 \quad 0 \leq x \leq h \\
& \beta^{2}=1+\hat{T}, \quad \hat{T}=\frac{2 \mu(1+v)^{2}}{(1-v)(1-2 v)} \frac{\kappa \alpha^{2}}{K} T_{0}
\end{aligned}
$$

The general solution of the differential equation (2.4) has the form

$$
T^{L}(x, p)=A_{1}+A_{2} \operatorname{sh}\left(\sqrt{\frac{p}{\kappa}} \beta x\right)+A_{3} \operatorname{ch}\left(\sqrt{\frac{p}{\kappa}} \beta x\right)
$$

in which $A_{1}, A_{2}, A_{3}$ are arbitrary constants.

Substituting $T^{L}(x, p)$ from (2.5) into (2.2), we obtain an inhomogeneous differential equation with respect to $u^{L}(x, p)$, after double integration, we obtain its general solution 


$$
u^{L}(x, p)=\frac{1+v}{1-v} \alpha \frac{1}{\sqrt{\frac{p}{\kappa}} \beta}\left(A_{2} \operatorname{ch}\left(\sqrt{\frac{p}{\kappa}} \beta x\right)+A_{3} \operatorname{sh}\left(\sqrt{\frac{p}{\kappa}} \beta x\right)\right)+A_{4} x+A_{5}
$$

where $A_{2}, A_{3}$ from (2.5), $A_{4}, A_{5}$ are new unknown values, depending on $p$.

Substituting $T^{L}(x, p)$ from (2.5) into (2.2), we obtain an inhomogeneous differential equation with respect to $u^{L}(x, p)$, after double integration, we obtain its general solution

$$
u^{L}(x, p)=\frac{1+v}{1-v} \alpha \frac{1}{\sqrt{\frac{p}{\kappa}} \beta}\left(A_{2} \operatorname{ch}\left(\sqrt{\frac{p}{\kappa}} \beta x\right)+A_{3} \operatorname{sh}\left(\sqrt{\frac{p}{\kappa}} \beta x\right)\right)+A_{4} x+A_{5}
$$

where $A_{2}, A_{3}$ are from (2.5), $A_{4}, A_{5}$ are new unknown values dependent on $p$.

Substituting (2.5) and (2.6) into the original (2.3), we obtain a connection between $A_{1}$ and $A_{4}$ of the form

$$
A_{1}=\frac{T_{0}}{p}-\frac{1-v}{1+v} \frac{\hat{T}}{\alpha} A_{4}
$$

Replacing $A_{1}$ by $A_{4}$ in (2.5) according (2.8) we obtain the general solution for $T^{L}(x, p)$ from (2.2), (2.3)

$$
T^{L}(x, p)=\frac{T_{0}}{p}+A_{2} \operatorname{sh}\left(\sqrt{\frac{p}{\kappa}} \beta x\right)+A_{3} \operatorname{ch}\left(\sqrt{\frac{p}{\kappa}} \beta x\right)-\frac{1-v}{1+v} \frac{\hat{T}}{\alpha} A_{4}
$$

Thus, $u^{L}(x, p)$ from (2.6) and $T^{L}(x, p)$ from (2.8) with constants $A_{2-5}$ are general solutions of the system (2.2), (2.3), and the constants $A_{2-5}$ are found from the boundary conditions (1.6), (1.8), (1.10), (1.11), after applying the integral Laplace transform to them:

mechanical

$$
\begin{array}{ll}
x=h & u^{L}(h, p)=-\Delta^{L}(p)+u_{w}^{L}(p) \\
x=0 & u^{L}(x, p)=0
\end{array}
$$

temperature

$$
\begin{array}{rlrl}
x=h & K \frac{d T^{L}(h, p)}{d x} & =-f V \sigma_{x x}^{L}(h, p) \\
x=0 & K \frac{d T^{L}(0, p)}{d x}=k\left(T^{L}(0, p)-\frac{T_{0}}{p}\right) \\
\text { in which } & u_{w}^{L}(p)=-f V K^{*} \frac{\sigma_{x x}^{L}(h, p)}{p} \\
& & \sigma_{x x}^{L}(x, p) & =\frac{2 \mu(1-v)}{1-2 v} \frac{d u^{L}(x, p)}{d x}-\frac{2 \mu(1+v)}{1-2 v} \alpha\left(T^{L}(x, p)-\frac{T_{0}}{p}\right)
\end{array}
$$


Substituting (2.6) into (2.11) we obtain a connection between $A_{2}$ and $A_{5}$

$$
A_{5}=-\frac{1+v}{1-v} \frac{\alpha}{\sqrt{p / \kappa \beta}} A_{2}
$$

From (2.13) after substituting (2.9) into it we obtain the relation

$$
A_{4}=\frac{1+v}{1-v} \frac{\alpha}{\hat{T} \mathrm{Bi}}\left(\mathrm{Bi} A_{3}-\sqrt{\frac{p}{\kappa}} \beta h A_{2}\right), \quad \mathrm{Bi}=\frac{k h}{K}
$$

Substituting $A_{5}$ and $A_{4}$ from (2.15), (2.16) into (2.6), and (2.16) - into (2.9) we obtain $u^{L}(x, p)$ and $T^{L}(x, p)$ in the new form, depending only on $A_{2}$ and $A_{3}$

$$
T^{L}(x, p)=A_{2} \frac{1}{\mathrm{Bi}}\left(\sqrt{\frac{p}{\kappa}} \beta h+\operatorname{Bish} \sqrt{\frac{p}{\kappa}} \beta x\right)+A_{3}\left(\operatorname{ch} \sqrt{\frac{p}{\kappa}} \beta x-1\right)+\frac{T_{0}}{p}
$$

The constants $A_{2}$ and $A_{3}$ are determined by substituting (2.16), (2.17) into the boundary conditions (2.9) and (2.11), after which a system of linear algebraic equations is formed with respect to $A_{2}$ and $A_{3}$

$$
\sum_{j=1}^{2} a_{i j} A_{j+1}=b_{i} \quad i=1,2
$$

where $b_{i}, a_{i j} i, j=1,2$ are calculated from the formulas

$$
\begin{gathered}
a_{11}=\left(\hat{T} \operatorname{Bi}(\operatorname{ch} \sqrt{z}-1) h-h z+\hat{V} k_{w} \frac{h^{2}}{\kappa} \beta^{2}\right) \sqrt{z} \\
a_{12}=\operatorname{Bi}\left(\hat{T} h \sqrt{z} \operatorname{sh} \sqrt{z} h+h z-\hat{V} k_{w} \frac{h^{2}}{\kappa} \beta^{2}\right) \\
a_{21}=\frac{1-v}{1+v}\left(\operatorname{Bi} \hat{T} \operatorname{ch} \sqrt{z}-\hat{V} \beta^{2}\right) \sqrt{z} \\
b_{1}=-\frac{\hat{T} \operatorname{Bi}}{\alpha} z \Delta^{L}(p), \quad b_{2}=0 \\
z=\frac{p}{\kappa} h^{2}, \quad \hat{V}=\frac{f V \alpha}{K} \frac{2 \mu(1+v) h}{1-2 v}, \quad k_{w}=\frac{1-v}{1+v} \frac{K K^{*}}{\alpha \kappa} \beta^{2}
\end{gathered}
$$

Solving the system (2.18) with respect to the constants $A_{2}, A_{3}$, and substituting them into (2.17), (2.16), (2.13), we obtain Laplace transforms of temperature, displacements and stresses, which are not written out here.

After inversion of the resulting transforms $T^{L}(x, p), u^{L}(x, p), \sigma_{x x}^{L}(x, p)$, with the help of the inverse Laplace transform (2.1) of the solution of the problem under consideration $T(x, t)$, $u(x, t), \sigma_{x x}(x, t)$, it is convenient to write down in the form of convolutions 


$$
\begin{aligned}
& T(x, t)-T_{0}=\frac{1-v}{1+v} \frac{\hat{V} \beta^{2}}{\alpha h} \int_{0}^{t} \Delta(\tau) f_{T}^{0}(x, t-\tau) d \tau \quad 0 \leq x \leq h, \quad t>0 \\
& f_{T}^{0}(x, t)=\frac{1}{2 \pi i} \int_{\Gamma} \frac{N_{T}^{0}(x, z)}{t_{\kappa} R(z)} e^{z \tilde{t}} d z, \quad \tilde{t}=\frac{t}{t_{\mathrm{\kappa}}}, \quad t_{\mathrm{\kappa}}=\frac{h^{2}}{\kappa} \\
& N_{T}^{0}(x, z)=\sqrt{z}\left(\operatorname{Bish} \sqrt{z} \frac{x}{h}+\sqrt{z} \operatorname{ch} \sqrt{z} \frac{x}{h}\right)+\frac{1-v}{1+v} \hat{T} z\left(r(z)+\operatorname{Bich} \sqrt{z} \frac{h-x}{h}\right) \\
& R(z)=z r(z)-\hat{V} \beta^{2}\left(\left(1-k_{w}\right) r(z)-\mathrm{Bi}\right)+\hat{T} \mathrm{Bi} \sqrt{z} \operatorname{sh} \sqrt{z} \\
& r(z)=\operatorname{Bich} \sqrt{z}+\sqrt{z} \operatorname{sh} \sqrt{z} \\
& u(x, t)=-\int_{0}^{t} \Delta(\tau) f_{u}^{0}(x, t-\tau) d \tau \quad 0 \leq x \leq h, \quad t>0 \\
& f_{u}^{0}(x, t)=\frac{1}{2 \pi i} \int_{\Gamma} \frac{N_{u}^{0}(x, z)}{t_{\kappa} R(z)} e^{z \tilde{t}} d z, \quad \tilde{t}=\frac{t}{t_{\kappa}} \\
& N_{u}^{0}(x, z)=z r(z) \frac{x}{h}-\hat{V} \beta^{2}\left(\operatorname{Bich} \sqrt{z} \frac{x}{h}+\sqrt{z} \operatorname{sh} \sqrt{z} \frac{x}{h}-\mathrm{Bi}\right)- \\
& -\hat{T} \operatorname{Bi} \sqrt{z}\left(\operatorname{sh} \sqrt{z} \frac{h-x}{h}-\operatorname{sh} \sqrt{z}\right) \\
& \sigma_{x x}(x, t)=-\frac{2 \mu(1-v)}{(1-2 v) h} \int_{0}^{t} \Delta(\tau) f_{\sigma}^{0}(x, t-\tau) d \tau \quad 0 \leq x \leq h, \quad t>0 \\
& f_{\sigma}^{0}(x, t)=\frac{1}{2 \pi i} \int_{\Gamma} \frac{N_{\sigma}^{0}(x, z)}{t_{\kappa} R(z)} e^{z \tilde{t}} d z, \quad \tilde{t}=\frac{t}{t_{\mathrm{\kappa}}} \\
& N_{\sigma}^{0}(x, z)=z\left[\hat{T}_{*} r(z)+\hat{T} \operatorname{Bi} \hat{V}_{*} \operatorname{ch} \sqrt{z} \frac{h-x}{h}\right] \\
& \hat{T}_{*}=1+\frac{1-v}{1+v} \hat{T} \hat{V} \beta^{2}, \quad \hat{V}_{*}=\hat{T} \operatorname{Bi}\left(1-\frac{1-v}{1+v} \hat{V} \beta^{2}\right)
\end{aligned}
$$

where the integration contour $\Gamma=\left\{z:-i \infty+d t_{\kappa},+i \infty+d t_{\kappa}\right\}$ represents a straight line in the complex plane of the variable of integration $z$ parallel to the imaginary axis and spaced from it by an amount $d t_{\mathrm{K}}$ that is selected so that the integration contour passes to the right of all isolated singular points of the integrands. It should be noted that the stresses $\sigma_{x x}(x, t)$ depend on the $x$ coordinate according to formula (2.28) for $N_{\sigma}^{0}(x, z)$, in contrast to the corresponding uncoupled problem [15, 19], where they did not depend on.

The wear $u_{w}(t)$ calculation formula can be obtained from (1.6)

$$
\begin{array}{lr}
u_{w}(t)=k_{w} \hat{V} \beta^{2} \int_{0}^{t} \Delta(\tau) f_{w}^{0}(x, t-\tau) d \tau & t>0 \\
f_{w}^{0}(x, t)=\frac{1}{2 \pi i} \int_{\Gamma} \frac{N_{w}^{0}(x, z)}{t_{\mathrm{\kappa}} R(z)} e^{z \tilde{t}} d z, \quad \tilde{t}=\frac{t}{t_{\mathrm{\kappa}}}
\end{array}
$$


where $N_{w}^{0}(z)=r(z)$, and $r(z)$ from (2.22).

In the obtained formulas $T(x, t), u(x, t), \sigma_{x x}(x, t), u_{w}(t)$ for solving the problem there are contour quadratures (2.20), (2.24), (2.27), (2.30). In the complex plane of the integration variable $z$, the integrands of the contour quadratures (2.20), (2.24), (2.27), (2.30) are meromorphic functions that contain a countable set of poles. At infinity in the complex plane of the variable of integration, the integrands in (2.20), (2.24), (2.27), (2.30) behave as follows when $|z| \rightarrow \infty$

$$
\begin{array}{ll}
N_{T}^{0}(x, z) R^{-1}(z)=\frac{1-v}{1+v} \hat{T}+O\left(z^{-1 / 2}\right) & 0<x<h \\
N_{u}^{0}(x, z) R^{-1}(z)=\frac{x}{h}+O\left(z^{-1 / 2}\right) & 0<x<h \\
N_{\sigma}^{0}(x, z) R^{-1}(z)=\hat{T}_{*}+O\left(z^{-1 / 2}\right) & 0<x<h \\
N_{w}^{0}(z) R^{-1}(z)=O\left(z^{-1}\right) &
\end{array}
$$

The asymptotics (2.31) show that the quadratures (2.20), (2.24), (2.27) do not exist in the usual sense, but are understood as generalized [26]. To calculate the quadratures in (2.20), (2.24), (2.27), regularization of the integrands at infinity when $|z| \rightarrow \infty$ is performed with the estimates (2.31) taken into account. As a result, the quadratures are represented as a superposition of the regular part of the generalized component and the quadrature, existing in the usual sense

$$
\begin{gathered}
T(x, t)-T_{0}=\frac{1-v}{1+v} \frac{\hat{V} \beta^{2}}{\alpha h}\left(\frac{1-v}{1+v} \hat{T} \Delta(t)+\int_{0}^{t} \Delta(\tau) f_{T}(x, t-\tau) d \tau\right) \quad 0 \leq x \leq h, t>0 \\
f_{T}(x, t)=\frac{1}{2 \pi i} \int_{\Gamma} \frac{N_{T}(x, z)}{t_{\kappa} R(z)} e^{z \tilde{t}} d z, \quad N_{T}(x, z)=N_{T}^{0}(x, z)-\frac{1-v}{1+v} \hat{T} R(z) \\
u(x, t)=-\Delta(t) \frac{x}{h}-\int_{0}^{t} \Delta(\tau) f_{u}(x, t-\tau) d \tau \quad 0 \leq x \leq h, t>0 \\
f_{u}(x, t)=\frac{1}{2 \pi i} \int_{\Gamma} \frac{N_{u}(x, z)}{t_{\kappa} R(z)} e^{z \tilde{t}} d z, \quad N_{u}(x, z)=N_{u}^{0}(x, z)-\frac{x}{h} R(z) \\
\sigma_{x x}(x, t)=-\frac{2 \mu(1-v)}{(1-2 v) h}\left[\hat{T}_{*} \Delta(t)-\int_{0}^{t} \Delta(\tau) f_{\sigma}(x, t-\tau) d \tau\right] 0 \leq x \leq h, t>0 \\
f_{\sigma}(x, t)=\frac{1}{2 \pi i} \int_{\Gamma} \frac{N_{\sigma}(x, z)}{t_{\kappa} R(z)} e^{z \tilde{t}} d z, \quad N_{\sigma}(x, z)=N_{\sigma}^{0}(x, z)-\hat{T}_{*} R(z)
\end{gathered}
$$

where $N_{T}^{0}(x, z), N_{u}^{0}(x, z), N_{\sigma}^{0}(x, z), R(z)$ from the formulas (2.21), (2.25), (2.28), (2.22), $\hat{T}_{*}$ is given after (2.28).

To calculate the quadratures in (2.33), (2.35), (2.37), in which the integrand functions are meromorphic and decreasing at infinity in the complex plane of the variable of integration, according to estimates 


$$
\left\{\begin{array}{l}
N_{T}(x, z) \\
N_{u}(x, z) \\
N_{\sigma}(x, z)
\end{array}\right\} R^{-1}(z)=O\left(z^{-1 / 2}\right) \quad|z| \rightarrow \infty, \quad 0 \leq x \leq h
$$

the methods of the theory of functions of a complex variable [27] can be used. When implementing these methods, it becomes necessary to determine the poles of the integrands in (2.33), (2.35), (2.37) in the complex plane of the variable of integration.

3. Poles of integrands. The poles of the integrands in (2.33), (2.35), (2.37) coincide with the zeros $R(z)$ of (2.22) except for those zeros that are removable singular points of the integrands. To determine the zeros $R(z)$ in the complex plane $z=\xi+i \eta$, equation is solved

$$
R(z)=z r(z)-\hat{V} \beta^{2}\left(\left(1-k_{w}\right) r(z)-\mathrm{Bi}\right)+\hat{T} \mathrm{Bi} \sqrt{z} \operatorname{sh} \sqrt{z}=0
$$

where $\beta^{2}, \mathrm{Bi}, \hat{T}, \hat{V}, k_{w}$ from (2.15), (2.16), (2.18), $r(z)$ from (2.22).

In equation (3.1), the zeros $R(z)$ depend on four dimensionless parameters of the problem $\hat{V}, k_{w}, \hat{T}$, Bi since the fifth parameter $\beta^{2}$ is expressed in terms of $\hat{T}$ in (2.14). Using the experience of $[14,15]$, we will investigate the behavior of the zeros from (3.1) for fixed $k_{w}, \hat{T}, \mathrm{Bi}$ and variable parameter $\hat{V}$, which varies from 0 to $\infty$. Assuming $\hat{V}=0$ in (3.1) we obtain the equation

$$
z r(z)+\hat{T} \mathrm{Bi} \sqrt{z} \operatorname{sh} \sqrt{z}=0
$$

to determine the zero approximations $\zeta_{k}^{0}=\zeta_{k}(0) \quad k=0,1,2, \ldots$ of the roots of equation $(3.1) \zeta_{k}(\hat{V})$ $k=0,1,2, \ldots$. Equation (3.2) does not have convenient analytical solutions. Assuming $\mathrm{Bi}=0$ in (3.2), for the zero approximation of the roots $\zeta_{k} k=0,1,2, \ldots$ of (3.1), we can take

$$
\zeta_{k}^{0}=-(\pi k)^{2} \quad k=0,1,2, \ldots
$$

that does not depend on $k_{w}, \hat{T}$. Assuming $\mathrm{Bi}=\infty$ in (3.2), as the zero approximation of the roots $\zeta_{k} k=0,1,2, \ldots$ in $(3.1)$ when $\mathrm{Bi}>>1$, we can use equation

$$
\sqrt{z} \operatorname{ch} \sqrt{z}+\hat{T} \operatorname{sh} \sqrt{z}=0
$$

that when $\hat{T}=0$ has the analytical solution

$$
\zeta_{k}^{0}=-\pi^{2}(k+1 / 2)^{2} \quad k=0,1,2, \ldots
$$

For the averages $\mathrm{Bi}$ and $\hat{T} \neq 0$ for the definition of $\zeta_{k}^{0} k=0,1,2, \ldots,(3.2)$ is used.

Asymptotics $\zeta_{k}^{0}$ for large numbers $k$ has the form (3.3). From the above formulas (3.3), (3.5), and also from equation (3.4) it follows that all zero approximations of zeros $R(z)$ from (3.1) are located on the negative part of the real axis or at zero. Nevertheless, when changing $\hat{V}$ from 0 to $\infty$ for fixed $k_{w}, \mathrm{Bi}, \hat{T}$, first of all the first two poles $\zeta_{0}$ and $\zeta_{1}$ can be located: I - on the negative part of the real axis $\operatorname{Re}\left(\zeta_{0}, \zeta_{1}\right)<0, \operatorname{Im}\left(\zeta_{0}, \zeta_{1}\right)=0$ at $0<\hat{V}<\hat{V}_{\mathrm{I}}$; II - in the left half-plane 
$\operatorname{Re}\left(\zeta_{0}, \zeta_{1}\right)<0, \quad\left|\operatorname{Im}\left(\zeta_{0}, \zeta_{1}\right)\right|<\infty$ at $\hat{V}_{\mathrm{II}}<\hat{V}<\hat{V}_{\mathrm{III}} ;$ III - in the right half-plane $\operatorname{Re}\left(\zeta_{0}, \zeta_{1}\right)>0$, $\left|\operatorname{Im}\left(\zeta_{0}, \zeta_{1}\right)\right|<\infty$ at $\hat{V}_{\mathrm{II}}<\hat{V}<\hat{V}_{\mathrm{III}} ; \mathrm{IV}$ - on the positive part of the real axis $\operatorname{Re}\left(\zeta_{0}, \zeta_{1}\right)>0$, $\operatorname{Im}\left(\zeta_{0}, \zeta_{1}\right)=0$ at $\hat{V}_{\mathrm{III}}<\hat{V}<\infty$. As will be shown below, roman I, II denotes regions where $\operatorname{Re}\left(\zeta_{0}, \zeta_{1}\right)<0$ at $0<\hat{V}<\hat{V}_{\text {II }}$ which are called domains of stable solutions, and regions III, IV with $\operatorname{Re}\left(\zeta_{0}, \zeta_{1}\right)>0$ at $\hat{V}_{\mathrm{II}}<\hat{V}<\infty$ are called regions of unstable solutions. In Fig. 1 we give examples of the trajectories of the poles $\zeta_{0}(\hat{V})$ and $\zeta_{1}(\hat{V})$ with a change of $\zeta_{1}(\hat{V})$ from 0 to $\infty$ when $\mathrm{Bi}=1$ are fixed for three values of $\hat{T}=0 ; 0,01 ; 0,02$ (shown as solid, dashed and dot-dashed lines, respectively) and different $k_{w}=0.5$ (set of curves 1), 0.9 (2), $1.0(3), 1.35$ (4), 5.0 (5). The marked points indicate the location of the poles $\zeta_{0}(\hat{V})$ and $\zeta_{1}(\hat{V})$ at $\hat{V}=0$, punctured - at $\hat{V} \rightarrow \infty$. The crossed-out square marks the point of the trajectory, with the passage of which with the increasing of $\hat{V}$ the real poles $\zeta_{0}(\hat{V})$ and $\zeta_{1}(\hat{V})$ become a pair of complex conjugate poles, and vice versa. It should be noted that even a small change in the coefficient $k_{w}$, containing the ratio of the size parameters $K^{*}$ and $\alpha$, regulating respectively the wear and thermal expansion of the strip, leads to significant changes in the trajectories $\zeta_{0}(\hat{V})$ and $\zeta_{1}(\hat{V})$, to a lesser extent, of the others $\zeta_{k}(\hat{V})$ $k=2,3,4, \ldots$. When wear is prevalent (curves $5, \boldsymbol{6}$ ), then $\zeta_{0}, \zeta_{1}$ and even more $\zeta_{k} k=2,3,4, \ldots$ at $k_{w}>1$ are in regions I, II. The prevalence of the expansion of the strip from the incoming heat over wear $0<k_{w}<1$ (curves 1-4) leads to the fact that $\zeta_{0}$ and $\zeta_{1}$ go to the right half-plane in the region III, IV (Fig.1).

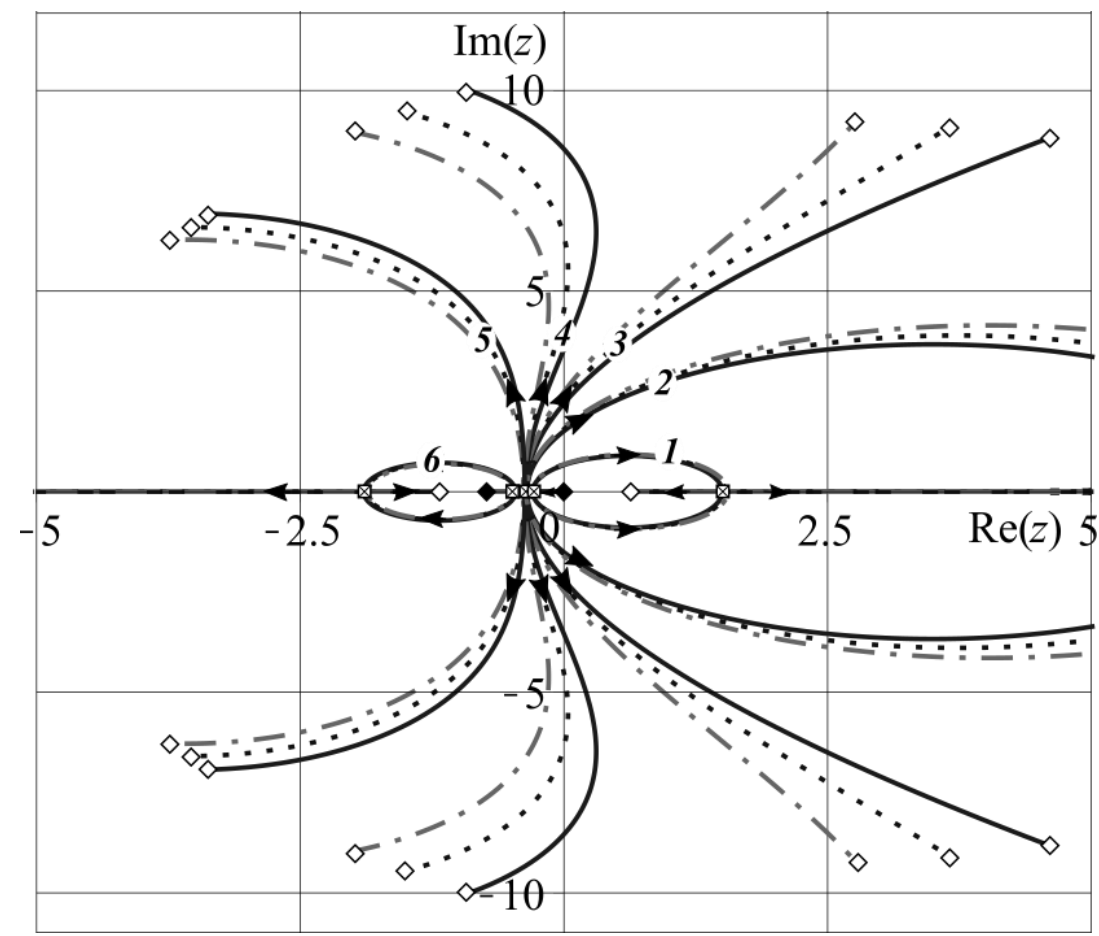

Fig. 1. Location of the initial boundary value problem eigenvalues in the complex plane 
An important feature of poles located in the complex plane in the regions II, III is noted, which for neighboring $\zeta_{0}$ and $\zeta_{1}$ consists in their complex conjugacy, i.e. $\zeta_{1}=\bar{\zeta}_{0}$ and $\zeta_{0}=\bar{\zeta}_{1}$.

According to the results of the investigation of the poles $\zeta_{0}(\hat{V})$ and $\zeta_{1}(\hat{V})$ in the complex plane, when $\hat{V}$ is changing from 0 to $\infty$, a remark should be made.

Remark. In contrast to problems with friction and heat generation from friction, but without wear, when the poles $\zeta_{0}$ and $\zeta_{1}$ at $\hat{V} \in[0, \infty)$ always remained on the real axis and did not come out into the complex plane $[14,15]$, in the corresponding problems, taking into account wear, friction and heat release from friction, the poles $\zeta_{0}$ and $\zeta_{1}$ move into the complex plane, and the poles themselves are complex conjugate $\zeta_{1}=\bar{\zeta}_{0}, \zeta_{0}=\bar{\zeta}_{1}$.

4. Formulas for the exact solution of the problem. Let the poles of the integrands $\zeta_{k}$ $k=0,1,2, \ldots$ in (2.33), (2.35), (2.37) be known. The calculation of the quadratures in (2.33), (2.35), (2.37) in this case reduces to calculating the sum of the residues at the poles of the integrands. Assuming that the poles $\zeta_{k} k=0,1,2, \ldots$ are single-valued, we obtain the following formulas for calculating the quadratures $(2.33),(2.35),(2.37)$

$$
\begin{gathered}
\frac{1}{2 \pi i} \int_{\Gamma} \frac{N_{a}(x, z)}{t_{\kappa} R(z)} e^{z \tilde{t}} d z=\sum_{k=0}^{\infty} B_{a}\left(x, \zeta_{k}\right) e^{\zeta_{k} \tilde{t}}, \quad \tilde{t}=\frac{t}{t_{\mathrm{\kappa}}} \\
B_{a}(x, z)=\frac{N_{a}(x, z)}{t_{\mathrm{\kappa}} R^{\prime}(z)}
\end{gathered}
$$

where $R^{\prime}(z)$ - derivative of $R(z)$. The index $a$ in (4.1), (4.2) takes literal images: if instead of $a$ it is written $T$, then in (4.1) we get the formula for computing (2.33); If $u$, then we get the formula for computing (2.35), if $\sigma$, then we get the formula for computing (2.37). If $\zeta_{k}$ and $\zeta_{k+1}$ $k=0,1,2, \ldots$ represent a complex conjugate pair $\zeta_{k+1}=\bar{\zeta}_{k} k=0,1,2, \ldots$, then

$$
B_{a}(x, z) e^{z \tilde{t}}=2 \operatorname{Re} \frac{N_{a}(x, z)}{t_{\kappa} R^{\prime}(z)} e^{z \tilde{t}}
$$

and the summation in (4.1) can be carried out over even numbers $k=2 n, n=0,1,2, \ldots$, for complex conjugates $\zeta_{k} k=0,1,2, \ldots$. Then, taking into account (2.32) - (2.37) and (4.2), (4.3) we obtain

$$
f_{a}(x, t)=\frac{1}{2 \pi i} \int_{\Gamma} \frac{N_{a}(x, z)}{t_{\kappa} R(z)} e^{z \tilde{t}} d z=\sum_{k=0}^{\infty} B_{a}\left(x, \zeta_{k}\right) e^{\zeta_{k} \tilde{t}}
$$

The solutions of the problem are written in the following series

$$
\begin{gathered}
T(x, t)-T_{0}=\frac{\hat{V} \beta^{2}}{\alpha h}\left(\frac{1-v}{1+v} \hat{T} \Delta(t)+\sum_{k=0}^{\infty} B_{T}\left(x, \zeta_{k}\right) D\left(\zeta_{k}, t\right)\right) \quad 0 \leq x \leq h, t>0 \\
u(x, t)=-\frac{x}{h} \Delta(t)+\sum_{k=0}^{\infty} B_{u}\left(x, \zeta_{k}\right) D\left(\zeta_{k}, t\right) \quad 0 \leq x \leq h, \quad t>0
\end{gathered}
$$




$$
\sigma_{x x}(x, t)=-\frac{2 \mu(1-v)}{(1-2 v) h}\left(\hat{T}_{*} \Delta(t)-\sum_{k=0}^{\infty} B_{\sigma}\left(x, \zeta_{k}\right) D\left(\zeta_{k}, t\right)\right) 0 \leq x \leq h, t>0
$$

where $B_{a}(x, z)$ are calculated according formulas (4.2) or (4.3), $D(z, t)$ using formula

$$
D(z, t)=\int_{0}^{t} \Delta(\tau) \exp \left(z(t-\tau) / t_{\mathrm{\kappa}}\right) d \tau \quad t>0
$$

After calculation of $f_{w}^{0}(t)$ in (2.30) using formula

$$
f_{w}^{0}(x, t)=\frac{1}{2 \pi i} \int_{\Gamma} \frac{N_{w}(z)}{t_{\kappa} R(z)} e^{z \tilde{t}} d z=\sum_{k=0}^{\infty} B_{w}\left(\zeta_{k}\right) e^{\zeta_{k} \tilde{t}}, \quad B_{w}=\frac{N_{w}(z)}{t_{\kappa} R^{\prime}(z)}
$$

and substituting it in (2.29), we obtain the formula for calculating the wear $u_{w}(t)$ of the coating material on the contact

$$
u_{w}(t)=\sum_{k=0}^{\infty} B_{w}\left(\zeta_{k}\right) D\left(\zeta_{k}, t\right) \quad t>0
$$

The horizontal displacements $w(x, t)$ are determined from (1.5), (1.7), (1.9) and after integration in (1.5) we obtain the formula

$$
w(x, t)=-f \mu^{-1} x \sigma_{x x}(h, t) \quad 0 \leq x \leq h, \quad t>0
$$

5. Analysis of the solution of the problem. Areas of stable and unstable solutions. An investigation of the solutions of the problem $T(x, t), u(x, t), \sigma_{x x}(x, t)$, represented by formulas (4.5) - (4.7), shows that in $\operatorname{Re}\left(\zeta_{k}\right)<0 \quad k=0,1,2, \ldots$ the solutions of the problem are stable and tend to a stationary state with increasing time $t$. If at least one $\zeta_{k} k=0,1,2, \ldots \operatorname{Re}\left(\zeta_{k}\right)>0$, then the amplitude of the solution increases indefinitely at $t \rightarrow \infty$, while at $\operatorname{Im}\left(\zeta_{k}\right) \neq 0$ is oscillating with frequency $\operatorname{Im}\left(\zeta_{k}\right)$, which indicates the instability of the solution of the problem. If we assume that the law of penetration $\Delta(t)$ is a bounded function

$$
m<\Delta(t)<M \quad m, M>0, \quad 0<t<\infty
$$

then for the integral (4.8) in this case the estimate $\left|D\left(\zeta_{k}, t\right)\right| \geq m\left|\frac{1-e^{\zeta_{k} \tilde{t}}}{\zeta_{k}}\right| \quad$ when $\quad \operatorname{Re}\left(\zeta_{k}\right)>0 \quad k=0,1,2, \ldots \quad t=\frac{t}{t_{\mathrm{\kappa}}}$

In the complex plane $z$, the pole trajectories $\zeta_{k}(\hat{V}) k=0,1,2, \ldots \hat{V} \in[0, \infty)$ in the left halfplane represent stable solutions $\left(\operatorname{Re}\left(\zeta_{k}\right)<0\right)$, and the regions I and II themselves are called the regions of stable solutions. Regions III and IV in the right half-plane $\left(\operatorname{Re}\left(\zeta_{k}\right)>0 \quad k=0,1\right)$ are regions of unstable solutions of the problem, since in region III the limits $\lim _{t \rightarrow \infty} T(h, t)$ and 
$\lim _{t \rightarrow \infty} \sigma_{x x}(h, t)$ do not exist because of $\operatorname{Im}\left(\zeta_{k}\right) \neq 0 \quad k=0,1$, and in region IV $\lim _{t \rightarrow \infty} T(h, t)=\lim _{t \rightarrow \infty} \sigma(h, t)=\infty$, since $\operatorname{Im}\left(\zeta_{k}\right)=0 \quad k=0,1$.

Areas I-IV of stable and unstable solutions of the problem are compactly represented in the space of dimensionless parameters $\hat{V}, k_{w}, \mathrm{Bi}, \hat{T} .$. In Fig. 2 on the plane $\left(\hat{V}, k_{w}\right)$ the regions of stable I, II and unstable III, IV solutions of the problem with pointing out the boundaries for $\hat{T}=0$ (in this case the boundary between regions is represented by a solid line), 0.1 (dotted line), 0.5 (dotdash line). The effect of the parameter $\mathrm{Bi}$ on the change of stability domains boundaries can be studied from comparison of Fig. 2a, b, c, which are presented for different values of $\mathrm{Bi}: \mathrm{a}) \mathrm{Bi}=1, \mathrm{~b}$ ) $\mathrm{Bi}=10, \mathrm{c}) \mathrm{Bi}=100$. When $k_{w} \rightarrow 0$ for $\mathrm{Bi}=1$ and $\mathrm{Bi}=100$, the boundaries of regions $\mathrm{I}-\mathrm{IV}$ converge on the axis $\hat{V}$ at the points $A_{1,2}$, respectively, with an abscissa $\hat{V}=2 \mathrm{Bi} /(2+\mathrm{Bi})$ that does not depend on $\hat{T}$.
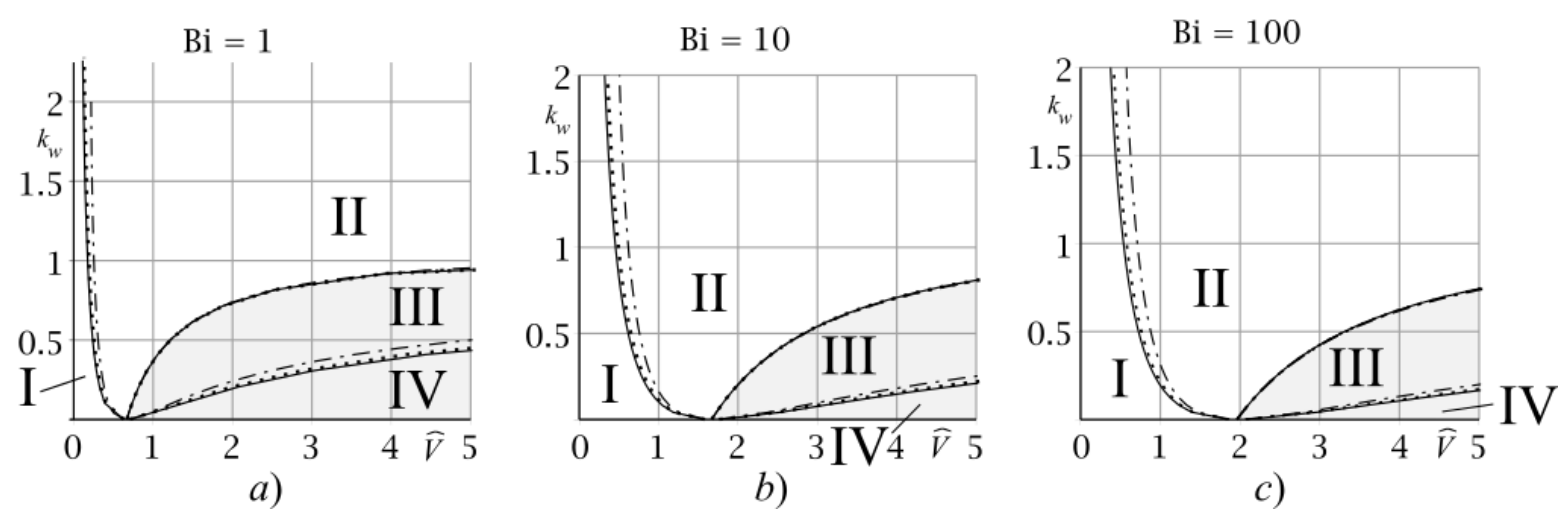

Fig. 2. Domains of stable and unstable solutions in the problem parameters space for different values of Biot number: $a$ ) $\mathrm{Bi}=1, b) \mathrm{Bi}=10, c) \mathrm{Bi}=100$

The graphs of the boundaries of regions I-IV (Figure 2) show that, depending on the value $k_{w}$ during change of $\hat{V}$ from 0 to $\infty$, it is possible to cross regions I-IV in different order ( $\mathrm{Bi}$ and $\hat{T}$ are fixed), for example: $\mathrm{I} \rightarrow \mathrm{II} \rightarrow \mathrm{III} \rightarrow \mathrm{IV}$ when $k_{w}<0.75$, for $k_{w}>0.75$ the order of intersection $\mathrm{I} \rightarrow \mathrm{II} \rightarrow \mathrm{III} \rightarrow \mathrm{II}$ or $\mathrm{I} \rightarrow \mathrm{II}$ etc.

6. Numerical analysis of the obtained solutions. Numerical analysis of the solutions of the coupled thermoelasticity problem under consideration on the sliding thermal and friction contact of a rigid body with an elastic coating under wear conditions at a contact is carried out by the formulas: temperature $T(x, t)(4.5)$, wear $u_{w}(t)$ (4.10) and stresses $\sigma_{x x}(x, t)(4.7)$ in the space of dimensionless parameters $\hat{V}, k_{w}, \mathrm{Bi}, \hat{T}$. Suppose that the maximum level of subsidence of the rigid half-plane $I$ into an elastic coating is given by $\Delta_{0}=0,1 h$, and the law of its penetration $\Delta(t)$, 
consisting of the active phase of the penetration in the time interval $0<t<t_{\varepsilon}$ and the passive phase of the penetration in the interval $t_{\varepsilon}<t<\infty$, described, for example, by the formulas

$$
\Delta(t)=\Delta_{0} \begin{cases}-1+e^{\varepsilon t} & 0<t<t_{\varepsilon} \\ 1 & t_{\varepsilon}<t<\infty\end{cases}
$$

where $t_{\varepsilon}=\varepsilon^{-1} \ln 2$ is the time of the end of the active penetration phase, $\varepsilon$ is the parameter of the penetration law.

The nature of the loss of stability in case of the uncoupled thermoelastic problem solutions $T(h, t), u_{w}(t), \sigma_{x x}(h, t)$ on sliding frictional contact depending on the parameters of the problem $\hat{V}$, $k_{w}$, Bi was described in detail in $[15,19]$. Here the effect of the parameters $V(\mathrm{~m} / \mathrm{s}), K^{*}\left(\mathrm{~m}^{2} / \mathrm{N}\right)$, $T_{0}(\mathrm{~K})$ on the obtained solutions of the coupled thermoelasticity problem on frictional sliding taking into account coating wear is studied. The following sliding characteristics are analyzed: temperature $\Theta(h, t)=T(h, t)-T_{0}$ from (4.5), contact stresses $p(t)=-\sigma_{x x}(h, t)$ from (4.7) that arise and develop in time on the sliding contact between the rigid half-plane $I$ and the coating, wear of the coating material $u_{w}(t)$ from (4.10), wear rate of the coating $\dot{u}_{w}(t)$ from (4.10). The coating is considered to be of a aluminum alloy with the following thermomechanical characteristics: $\mu=24.8 \mathrm{GPa}$, $v=0.34, \quad \kappa=88.1 \cdot 10^{-6} \mathrm{~m}^{2} / \mathrm{s}, \quad \alpha=22.9 \cdot 10^{-6} 1 / \mathrm{K}, \quad K=209.3 \mathrm{~W} /(\mathrm{m} \cdot \mathrm{K}), \quad f=0.47, \quad h=25 \mathrm{~mm}$, $\Delta_{0}=0.01 \mathrm{~h}=0.25 \mathrm{~mm}$. Wear of the coating surface ends at $t=t_{w}$, when the contact stresses turn to zero $\left(p\left(t_{w}\right)=-\sigma_{x x}\left(h, t_{w}\right)=0\right)$; in other words, $t_{w}$ is the wear time of the coating.

The effect of the wear coefficient $K^{*}$ and the initial temperature $T_{0}$ on the solutions of the problem under consideration is illustrated in Fig. $3 a-c$, which show the graphs $\Theta(h, t)=T(h, t)-T_{0}$, $p(t), u_{w}(t)$ for the following parameters of the problem: $V=3.22 \mathrm{~mm} / \mathrm{s} \quad(\hat{V}=0.86085)$, $\mathrm{Bi}=11.9446 . V=3.22 \mathrm{~mm} / \mathrm{s}(\hat{V}=0.86085), \mathrm{Bi}=11.9446$. The graphs on Fig. $3 a$ are constructed at $K^{*}=7.5 \cdot 10^{-12} \mathrm{~m}^{2} / \mathrm{N}\left(k_{\mathrm{w}}=0.3833\right)$; Fig. $3 b$ at $K^{*}=1.5 \cdot 10^{-11} \mathrm{~m}^{2} / \mathrm{N}\left(k_{\mathrm{w}}=0.7665\right)$; Fig. $3 c$ at $K^{*}=2.25 \cdot 10^{-11} \mathrm{~m}^{2} / \mathrm{N}\left(k_{\mathrm{w}}=1.1498\right)$. The solid line in Fig. $3 a-c$ represents the graphs of the solution of the present coupled thermoelasticity problem at $T_{0}=0 \mathrm{~K}(\hat{T}=0)$, which coincide with the graphs for the solution of the corresponding uncoupled problem; the dashed line plots the solution at $T_{0}=300 \mathrm{~K}(\hat{T}=0.0279)$, the dash-dot line plots the solution at $T_{0}=525 \mathrm{~K}(\hat{T}=0.0489)$. 

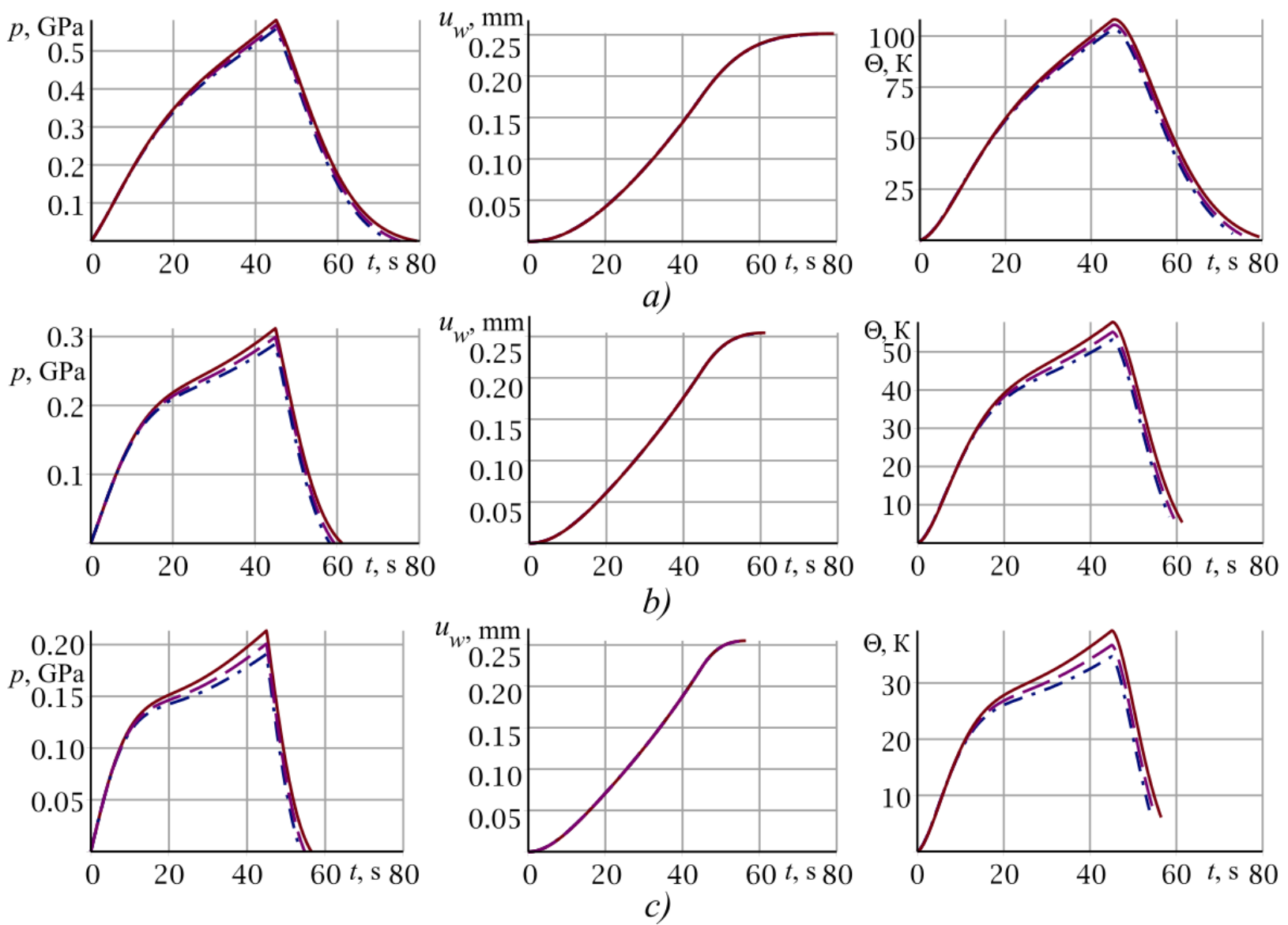

Fig. 3. Contact pressure $p(t)$, wear $u_{w}(t)$, temperature $\Theta(h, t)=T(h, t)-T_{0}$ for different values of wear coefficient: $\left.\left.a) K^{*}=7.5 \cdot 10^{-12} \mathrm{~m}^{2} / \mathrm{N}\left(k_{\mathrm{w}}=0.3833\right), b\right) K^{*}=1.5 \cdot 10^{-11} \mathrm{~m}^{2} / \mathrm{N}\left(k_{\mathrm{w}}=0.7665\right), c\right)$

$$
K^{*}=2.25 \cdot 10^{-11} \mathrm{~m}^{2} / \mathrm{N}\left(k_{\mathrm{w}}=1.1498\right)
$$

Conclusion. Mathematical modelling of a coating wear process was carried out based on the solution of a problem of the coupled thermoelasticity theory. The Laplace integral transform and complex analysis methods were used to present the solution in the form of series over eigenvalues of the corresponding initial boundary value problem.

It was found that eigenvalues of the problem are strongly influenced by the thermomechanical coupling parameter of the problem. From the other hand, the boundary between regions of stable (I, II) and unstable (III, IV) solutions of the problem remains unchanged for any values of the thermomechanical coupling parameter. From the analysis of the solutions, it was found that increase in the thermomechanical parameter of the coupling of the problem, as well as an increase in the wear coefficient, leads to a decrease in both the temperature and the stresses at the contact. 


\section{References}

1. Biot, M.A. Thermoelasticity and irreversible thermodynamics. Journal of Applied Physics, 1956, vol. 27, no. 3, pp. 240-253.

2. Deresiewicz, H. Solution of the equations of thermoelasticity. Proc. 3rd U.S. Nat. Congr. Appl. Mech. ASME. Providence, Brown University, 1958, pp. 287-291.

3. Chadwick, P. Thermoelasticity. The dynamical theory. Progress in Solid Mechanics. eds. I.N. Sneddon, R. Hill. Amsterdam, North-Holland Publishing Company, 1960, pp. 263-328.

4. Boley, B.A., Weiner, J.H. Theory of thermal stresses. New York, London, John Wiley and Sons, Inc. 1960.

5. Nowacki, V. Dynamic problems of thermoelasticity. Moscow, Mir, 1970, transl. from Polish, $256 \mathrm{p}$.

6. Nickell, R.E., Sackman J.L. Approximate Solutions in linear, coupled thermoelasticity. Journal of Applied Mechanics, 1968, vol. 35, no. 2, pp. 255-266.

7. Oden, J.T. Finite element analysis of nonlinear problems in the dynamical theory of coupled thermoelasticity. Nuclear Engineering and Design, 1969, vol. 10, no 4, pp. 465-475.

8. Prevost, J.H., Tao, D. Finite element analysis of dynamic coupled thermoelasticity problems with relaxation times. Journal of Applied Mechanics, 1983, vol. 50, no. 4a, pp. 817-822.

9. Carter, J.P., Booker, J.R. Finite element analysis of coupled thermoelasticity. Computers \& Structures, 1989, vol. 31, no. 1, pp. 73-80.

10. Hacquin, A., Montmitonnet, P., Guillerault, J.P. A steady state thermo-elastoviscoplastic finite element model of rolling with coupled thermo-elastic roll deformation. Journal of Materials Processing Technology, 1996, vol. 60, no. 1, pp. 109-116.

11. Repka, M., Lion, A. Simulation of the coupled thermo-elastic behavior of constrained films in differential scanning calorimetry using the finite element method. Thermochimica Acta, 2014, vol. 581, pp. 62-69.

12. Gribanov, V.F., Panichkin, N.G. Coupled and dynamic thermoelasticity problems. Moscow, Mashinostroeniye, 1984, 151 p. (in Russian)

13. Alexandrov, V.M., Annakulova, G.K. A contact problem of thermo-elasticity with wear and heat release caused by friction. Trenie i Iznos, 1990, vol. 11, no. 1, pp. 24-28. (in Russian)

14. Alexandrov, V.M., Annakulova, G.K. Interaction between coatings of a body with deformation, wear, and heat release due to friction. Trenie i Iznos, 1992, vol. 13, no. 1, pp. 154-160. (in Russian)

15. Evtushenko, A.A., Pyryev, Y.A. Influence of wear on the development of thermoelastic instability of a frictional contact. Proceedings of the Russian Academy of Sciences. Mechanics of solids, 1997, no. 1, pp. 114-121. (in Russian)

16. Pyryev, Y.A., Grilitsky, D.V. The non-stationary problem of the frictional contact for a cylinder taking into account heat release and wear. Applied Mathematics and Technical Physics, 1996, p. 37, no. 6, pp. 99-104.

17. Pyryev, Y.A. Frictional contact of a cylinder with a clip, taking into account inertia, heat release and wear. Physico-chemical mechanics of materials, 2000, vol. 36, no. 3, pp. 53-58. 
18. Awrejcewicz, J., Pyryev, Y. Thermoelastic contact of a rotating shaft with a rigid bush in conditions of bush wear and stick-slip movements. International Journal of Engineering Science, 2002, vol. 40, no. 10, pp. 1113-1130.

19. Zelentsov, V.B., Mitrin, B.I., Lubyagin, I.A. Influence of wear on frictional heating and appearance of thermoelastic instability of a sliding contact. Computational Mechanics of Continuous Media, 2016, vol. 9, no. 4, pp. 430-442.

20. Strömberg, N., Johansson, L., Klarbring, A. Derivation and analysis of a generalized standard model for contact, friction and wear. International Journal of Solids and Structures, 1996, vol. 33, no. 13, pp. 1817-1836.

21. Andrews, K.T., Shillor, M., Wright, S., Klarbring, A. A dynamic thermoviscoelastic contact problem with friction and wear. International Journal of Engineering Science, 1997, vol. 35, no. 14, pp. 1291-1309.

22. Strömberg, N. Finite element treatment of two-dimensional thermoelastic wear problem. Computer Methods in Applied Mechanics and Engineering, 1999, vol. 177, no. 3-4, pp. 441-455.

23. Kovalenko, A.D. Introduction to thermoelasticity. Kiev, Naukova Dumka, 1965, 204 p.

24. Archard, J.E. The temperature of rubbing surfaces, Wear, 1959, vol. 2, no. 6, pp. 438455.

25. Ditkin, V.A., Prudnikov, A.P. Operational calculus. Moscow, Vishaya Shkola, 1975, $407 \mathrm{p}$.

26. Brychkov, Y.A., Prudnikov, A.P. Integral transformations of generalized functions. Moscow, Nauka, 1977, 287 p.

27. Gurvits, A., Courant, P. Theory of functions. Moscow, Nauka, 1968, 648 p.

28. Zabreiko, P.P. Integral equations. Moscow, Fizmatlit, 1968, 448 p.

Authors:

Zelentsov Vladimir Borisovich, Head of Center, Scientific Equipment Joint Use Center, Research and Education Center "Materials", Don State Technical University (1 Gagarin sq., Rostov-on-Don, Russian Federation), Candidate of Science in Physics and Maths, Senior researcher

Mitrin Boris Igorevich, Junior researcher, Functionally graded and composite materials laboratory, Research and Education Center "Materials", Don State Technical University (1 Gagarin sq., Rostov-on-Don, Russian Federation), Candidate of Science in Physics and Maths

Lubyagin Igor Anatolyevich, Junior researcher, Functionally graded and composite materials laboratory, Research and Education Center "Materials", Don State Technical University (1 Gagarin sq., Rostov-on-Don, Russian Federation)

Aizikovich Sergey Mikhailovich, Head of Laboratory, Functionally graded and composite materials laboratory, Research and Education Center "Materials", Don State Technical University (1 Gagarin sq., Rostov-on-Don, Russian Federation), Doctor of Science in Physics and Maths, Senior researcher. 
УДК $004.942:: 539.621: 517.958: 517.442$

\section{Математическое моделирование термоупругого поведения покрытия с учетом разогрева и износа от трения*}

\section{В.Б. Зеленцов, И.А. Лубягин, Б.И. Митрин, С.М. Айзикович ${ }^{* *}$}

Донской государственный технический университет, Ростов-на-Дону, Российская Федерация

В работе описывается применение метода интегральных преобразований для решения квазистатической контактной задачи об износе покрытия. Разогрев и износ покрытия от трения происходит при скольжении жёсткого тела по его поверхности. Задача рассматривается в рамках связанной теории термоупругости. Решение задачи построено в виде контурных квадратур обратного преобразования Лапласа. В результате вычисления полученных квадратур, решение записано в виде рядов по полюсам их подынтегральных функций. Проведено исследование полюсов подынтегральных функций решения задачи в зависимости от четырех безразмерных параметров задачи. Подробно изучена зависимость полученных решений в зависимости от безразмерных и размерных параметров задачи. Приведены численные примеры полученных решений - контактных напряжений, смещений, температуры материала покрытия.

Ключевые слова: покрытие, трение, износ, фрикционное тепловыделение, термоупругость, преобразование Лапласа, контурный интеграл

\section{Авторы:}

Зеленцов Владимир Борисович, руководитель Ресурсного центра коллективного пользования НОЦ «Материалы» Донского государственного технического университета (РФ, 344000, г. Ростов-на-Дону, пл. Гагарина, 1), кандидат физико-математических наук, старший научный сотрудник

Митрин Борис Игоревич, младший научный сотрудник Лаборатории функциональноградиентных и композиционных материалов НОЦ «Материалы» Донского государственного технического университета (РФ, 344000, г. Ростов-на-Дону, пл. Гагарина, 1), кандидат физико-математических наук

Лубягин Игорь Анатольевич, младший научный сотрудник Лаборатории функциональноградиентных и композиционных материалов НОЦ «Материалы» Донского государственного технического университета (РФ, 344000, г. Ростов-на-Дону, пл. Гагарина, 1)

Айзикович Сергей Михайлович, заведующий Лабораторией функционально-градиентных и композиционных материалов НОЦ «Материалы» Донского государственного технического университета (РФ, 344000, г. Ростов-на-Дону, пл. Гагарина, 1), доктор физикоматематических наук, старший научный сотрудник

\footnotetext{
* Работа выполнена в рамках Государственного задания Минобрнауки России № 9.1481.2017/4.6 и грантов РФФИ № 16-07-00929-a, 17-07-01376-a.

**E-mail: vbzelen@gmail.com, bmitrin@dstu.edu.ru, hammavet@gmail.com, saizikovich@gmail.com
} 